\title{
Managing population-environment systems: Problems of institutional design
}

Geoffrey McNicoll

Population Council

Follow this and additional works at: https://knowledgecommons.popcouncil.org/departments_sbsr-pgy

Part of the Demography, Population, and Ecology Commons, Environmental Public Health Commons, and the Sustainability Commons

How does access to this work benefit you? Let us know!

\section{Recommended Citation}

McNicoll, Geoffrey. 2000. "Managing population-environment systems: Problems of institutional design," Policy Research Division Working Paper no. 139. New York: Population Council. Version of record: https://www.jstor.org/stable/3115271 


\section{M anaging Population- Environment Systems: Problems of Institutional D esign}

G eoffrey M cNicoll 


\section{Managing Population-Environment Systems: Problems of Institutional Design}

Geoffrey McNicoll

Geoffrey McNicoll is Senior Associate, Policy Research Division, Population Council. 


\begin{abstract}
In population-environment systems human activity is inherently part of the system rather than something to be minimized in order to maintain or restore "natural" environmental conditions. Issues arising in managing such systems are discussed in this paper. Three preliminary sets of problems are first dealt with. The system's boundaries must be identified, defining its human participants and its ecological content. Procedures for monitoring demographic and environmental change in the system must be set up. And consensus must be reached on how to evaluate that change. Each of these tasks calls for technical knowledge of demographic and ecological relationships (and assessment of uncertainties); in addition each has important political and administrative dimensions. Unclear or contested boundaries, large numbers of participants, complex system dynamics and outcome indicators, and unequal stakes by participants complicate the management task. Among the general problems of designing governing institutions for large and complex population-environment systems are devising compensation arrangements to remedy major asymmetries in returns to participants, enforcing compliance to agreed access rules, and building in adaptability to changing knowledge and circumstances.
\end{abstract}

This material may not be reproduced without written permission from the author. 
Human intervention in the Earth's natural (ecological and physical) systems brings with it problems of management - both of the intervention and, more fundamentally, of the system. The main exception, aside from interventions that are essentially trivial as a matter of relative scale, occurs where the effects of an intervention are unrecognized or unvalued, and hence elicit no feedback response from the intervenors or from others who are affected. In such a case negative outcomes on both sides may ensue: ecological degradation on the one hand, adverse repercussions on human wellbeing on the other. Human prehistory and much of human agrarian history, far from demonstrating a uniform harmony with the natural environment or being a steady course of environmental transformation to yield improved human welfare, probably witnessed many of these deteriorating but nonmanaged population-environment relationships. For example, hunter-gatherers, making up minuscule populations, may have transformed whole ecologies by exterminating top predators or introducing new fire regimes. ${ }^{1}$ In a later period, agrarian settlement brought new human diseases, likely acquired from domesticated animals and rendered endemic by the new living conditions, imposing a worsened demographic regime. Increasingly, however, the form and scale of environmental interventions are nontrivial and have effects that are recognized or can be anticipated. Management issues then come to the fore and must be dealt with.

Those issues can be simply categorized. First is that of delimiting the boundaries of a population-environment system - not in any cut-and-dried fashion, since the interactions are ramified, play out over long periods, and may be poorly understood, but in a way that takes into account both scientific knowledge (and uncertainty) and political and administrative circumstances. Second is the task of monitoring population and environmental change in particular systems, where again both scientific and political/administrative factors necessarily enter. And third is the problem of how to evaluate environmental and demographic change. These issues are treated in the next three sections of this paper. I then draw on that discussion to consider some general problems (equity, compliance, and adaptability) met with in the design of governing institutions for population-environment systems.

\section{Delimiting Population-EnVironment Systems}

Vaclav Smil (2000), in the course of rejecting "willingness to pay" as a satisfactory measure of environmental services, concedes the utility of that measure for "nar- 
rowly defined, immediate and short-term concerns on a local or regional level, or when dealing with crises or catastrophes on a larger scale" (p. 9). These are just the kinds of population and environment (P-E) systems where boundaries are moderately easy to discern and defend. For example, the centuries-old common-pool resource (CPR) regimes discussed by Ostrom (1990), which have maintained the ecological stability and productivity of fragile local environments in the face of pressures of grazing or irrigation demand, apply to clearly prescribed areas and participants. Or again, pollution from the runoff of agricultural chemicals that affect local fisheries presents a set of relationships fairly readily defined and regionally circumscribed. And as a third case, the realization that release of chlorofluorocarbon gases had a destructive effect on atmospheric ozone allowed the delimitation of a human-cum-natural system theretofore unrecognized - one that was global in extent but very narrow in content. By contrast, many P-E systems that enter casual discussion and even the technical literature have notably hazy boundaries. That is the case, for example, of the systems implicit in the estimates by Vitousek et al. (1997) of the extent of human domination of the planet. The indicators of such impact include the proportion of the Earth's land surface "transformed by human activity," the anthropogenic share of atmospheric carbon dioxide, and the proportion of marine fisheries that are fully exploited or depleted.

The boundaries we need to be concerned with are those that delimit the natural system and the relevant human population(s).

\section{Physical boundaries}

The relevant physical boundaries for a P-E system are not decreed by nature. Their choice entails judgments of how closely system autonomy needs to be approachedthat is, which spillovers can be ignored or dealt with in other ways and which should be contained within the system. And they require assessment of management feasibility: ecologically defined limits may or may not describe a manageable system. Making ecological and administrative boundaries coincide by setting up an ad hoc administrative authority that spans the ecologically defined domain can be a major initial step in combating P-E degradation. Seriously endangered ecologies often result from failures on this score, at least in a proximate sense. ${ }^{2}$ Emergent institutional arrangements by which individuals threatened by environmental overexploitation devise measures to collec- 
tively limit demand on the system make sense only to the extent that the relevant resource is effectively spanned by those arrangements.

Physical boundaries may be set in such a way as to preserve a section of some particular environment—say, a biodiversity "hot spot" or an area of wetlands—or to protect a particular species. Typically, a conservation or wilderness area would be defined legislatively, but in a way intended to bind future generations. The idea is to remove such environments from being subject to market-based tradeoffs and (further) political compromises, even if the initial delimitation was itself a political decision. More generally, for any environmental domain there is likely to be a variety of interest groups with conflicting stakes in where the boundaries of a P-E system are set: indeed, deciding on boundaries may be the issue on which the principal political struggles take place.

Cultural factors have a part in setting a system's physical boundaries - privileging certain animal species, for instance. Such rationales, perhaps scientifically arbitrary, may yield powerful defenses of system boundaries. ${ }^{3}$ But dispensing with hard ecology also carries risks. One recent writer on this subject, noting, in postmodernist fashion, that humans "construct" their landscapes, goes on to say: "If so, we can hardly say that there are any boundaries, or even limits to the numbers of possible 'worlds', except, perhaps, those handed down to us or reconstructed by us. And even those boundaries, reified as they are, are constantly shifting, as we change our individual and collective identities, and as our identities are changed for us" (Lipschutz 1996: 254). This is the route to policy immobility.

\section{Social boundaries}

What is the population in a P-E system? In common usage, it is those who trample the plants or hunt the wildlife - the P of IPAT, to use the well-known Ehrlich-Holdren formula. But that casual association of people and impact cannot bear much scrutiny. As a step toward greater precision, we might identify three populations involved in a specified system, conceptually distinct although often substantially overlapping (and, as a theoretical possibility, fully coinciding):

P1: the persons whose actions directly impinge on the environmental component of the system-the Ehrlichian $P$; 
P2: the population benefiting from that intervention, and probably countenancing it; presumably $\mathrm{P} 2 \supset \mathrm{P} 1$;

P3: the population harmed or at increased risk of harm by any resulting environmental change.

The three may not be well-defined populations in simple demographic terms, since responsibility, benefit, and harm are not dichotomous factors; each population would usually be a fuzzy set. But it is convenient to assume non-fuzziness. P2 and P3 together (that is, P2 $\cup \mathrm{P} 3$ ) are the stakeholders in the system.

In a "tragedy of the commons" the three populations coincide. The farmers pumping irrigation water from an aquifer at an unsustainable rate without the means of enforcing conservation measures on their fellows have no incentive to limit their own use of water. The costs of deepening their wells as the water table falls, and eventually of facing the exhaustion of groundwater supply, fall on all the users-equally so, in the stylized version of the tragedy. (If the time to exhaustion is long enough, however, the cost is transferred to a future generation, notionally separating out P3.)

In less-stylized P-E systems, P3 is likely to be partly displaced. One group or community receives net benefits, another has to bear net costs. Upstream agricultural or settlement activities lead to larger and more frequent downstream floods-and with the numbers of those affected (P3) swollen by risky settlement on floodplains. For purposes of P-E management, the system boundaries may or may not include that downstream environment and its population. ${ }^{4}$

In another familiar instance, a forest concession may be clear-felled to yield immediate returns to well-connected operators, leaving a severely degraded ecosystem that is of little value to those who formerly harvested forest products and that represents an effective enclosure and destruction of part of the country's natural capital. The same ecological outcome can also follow from aspiring settlers' or agroindustrialists' burning forest land for expansion of smallholder or plantation agriculture-the likely origin of the massive forest fires that have been experienced in recent years in Southeast Asia. Both sources of deforestation are found in major tropical forests such as those of Kalimantan or the Amazon. The loss of natural capital is borne in some sense by the national population; in the case of the Indonesian forest fires, at least short-run costs 
were borne widely across the economies and populations of Southeast Asia. The P-E system for management purposes, however, is probably best delimited by provincial or national boundaries.

There are of course P-E systems whose social boundaries are necessarily global in extent-where $\mathrm{P} 3$, if not $\mathrm{P} 2$, is the world population. Problems of atmospheric ozone depletion and greenhouse warming are prominent examples, but responses to many other environmental problems are being sought through cooperation or treaty commitment at the global level.

Trade and technology transfers and other interactions spread economic development and diffuse costs, blurring distinctions between P2 and P3. The concept of an "ecological footprint" introduced by Wackernagel and Rees (1996) can be seen as an effort to unbundle those costs and reattribute them. The footprint of a given population at a specified standard of living is the equivalent area that can provide the resources and waste assimilation needed to sustain those numbers at that living standard. ${ }^{5}$ By and large, industrialized countries incur an ecological deficit in this sense: they draw on resource and environmental services well in excess of what can be supplied within their own borders. As Rees (1996: 110) puts it, "[I]n purely ecological terms, modern settlements have become the human equivalent of cattle feedlots." (Balancing the ecological books in this way, however, takes no account of the most obvious "surplus" of those same countries: the positive externalities flowing from their technological advances.)

In any real set of circumstances precision on population boundaries is probably unattainable. Much of social life is concerned with transfers of benefits and costs of human activity, whether through the market or through other kinds of relationship. There are gradations of benefits and harms over the population, not even necessarily commensurable. Assignment of those experiencing such effects to a particular subgroup, or as being external to the system, is often an arbitrary decision, and sometimes a contested one.

Intangible or subjective benefits and harms are a further complication. Extinction of a species or a more general loss of biodiversity may have scant economic repercussions but still cause dismay or regret over a wide population, often in distant countriesplausibly larger numbers than would be located through a willingness-to-pay inquiry. (See Smil [2000] for a discussion of this issue.) 


\section{Monitoring Population And EnVironmental Change}

In environmental systems the monitoring problem consists first in assessing overall change in the system - that is, in its state variables - and second in assessing the human contribution to that change. By implication, this human contribution is generally taken to be damaging, so that the smaller the intervention - the smaller the I of IPAT - the better. In P-E systems, in contrast, humans are inherently part of the system, not (or not necessarily) despoiling interlopers. They add one or more elements to the vector of state variables. For these systems we discard the notion of a pristine, human-free natural world as the standard from which to measure change. In its place is an interactive system in which human exploitation of environmental resources is the norm. The monitoring problem consists in gauging changes in indicators of quantity (such as forested area) and quality (such as level of biodiversity) on the environmental side and changes in human numbers and wellbeing on the population side.

Environmental change, it may be supposed, is easy to assess. The rate of deforestation, for example, is ascertainable by aerial photography or satellite imaging. Yet ambiguities may remain, at the very least calling for careful "ground-truthing." Thus the standard, environmental-system view of deforestation in West Africa is of expanding human agricultural settlements at the expense of primary forest, with drastic reductions of forest area routinely cited in support, whereas a recent study (Leach and Fairhead 2000) suggests that such a picture is erroneous in every particular. Human-caused deforestation, this study finds, is grossly exaggerated in both international agency statistics and popular understanding. ${ }^{6}$ As another example, estimates of the area burned in the 1997 forest fires in Indonesia, all based on remote-sensing data, range over an order of magnitude, from 100,000 ha. to 1.7 million ha. (Harwell 2000: 308-309).

P-E system management also calls for monitoring the human component, both numbers and wellbeing. Measurement of population change is conceptually straightforward, but the monitoring task is to separate out the change that is relevant to the system. Migration, for example, may be a routine process in a more-or-less sustainable P-E system, with no connection to degradation. This would often be true of circular labor migration, shifting cultivation, and transhumance. Rural-urban migration is another process that need have little to do with environmental degradation. ${ }^{7}$ The principal situation 
in which environmental change induces an "exit" strategy is in the case of so-called environmental refugees-persons displaced by long-term overexploitation of resources or by sudden natural disaster.

Even where degradation is clearly occurring, human responsibility for it may be exaggerated. To many observers, for instance, the serious ecological degradation seen in the Himalayas-alpine soil erosion and landslides-is linked to ill-advised land-use practices by subsistence hill farmers. Ives and Messerli (1989), however, argue that natural geophysical processes are probably several orders of magnitude more important than human interventions. They believe hill farmers contribute little to downstream siltation and flooding - the processes that over the centuries, and long before the era of rapid population growth, created the fertile plains of northern India and Bangladesh.

Assessing changes in human wellbeing is the other P-monitoring task, drawing on standard methods of measuring income, poverty, health, mortality, and perhaps other dimensions of welfare. One component of welfare is derived directly from exploitation of environmental resources through activities that have to be rationed to a sustainable level. This may call for detailed monitoring of those activities. Cultural or aesthetic appreciation of the natural (or built) environment also contributes to welfare.

In most P-E systems of concern to us, there is a lot more going on than is evident to most participants. We sometimes do not know enough about the system to be certain of what we should be monitoring. For example, despite the large research effort on the greenhouse problem, many uncertainties surround the workings of carbon sinks. Again, in some of the world's major river basins where agricultural land has been degraded through over-irrigation and resulting salination, the salt-system dynamics are only now being understood. It is found that the period between, say, a significant extension of irrigated land and establishment of a new system equilibrium may be measured in decades: irrespective of what remedial action is taken, the monitoring effort for a lengthy time will track an environmental decline. ${ }^{8}$

The monitoring task is not purely technical. Since there are potential winners and losers in a P-E system, inescapable political issues are involved in any monitoring regime- to do with who monitors and with checks on accuracy and controls on cheating. These are taken up in the discussion of compliance below. 


\section{VALUATION ISSUES}

Beneath its political and administrative complexities, management of a P-E system is formally a control problem. The system, characterized by its state and control variables, evolves over time according to more-or-less known dynamics. We seek a time trajectory of control variables to meet some objective criterion-which in turn is a function of the state and control variables. A proper specification of that function has to assign values to those variables. In theory, that would mean setting tradeoffs or rates of substitution among changes in human numbers, health, and economic status, and in relevant environmental indexes: ethically an all-but-impossible task. In real-world systems of any complexity, no such explicit specification is attempted; incommensurables are left as they are. But inescapably, judgments that roughly correspond to assumptions about those tradeoffs are nonetheless being made. Some of the issues raised in these judgments are described briefly below.

\section{Precaution and regret}

The precautionary principle, a mainstay of environmentalist thinking, argues for taking early action to safeguard against later regret even in advance of full knowledge of systemic relationships. ${ }^{9}$ It cannot tell us how much to pay to lessen uncertainty-where even the probability distribution of an event is unknown. This is sometimes referred to as the "planner's dilemma": how to choose a cutoff point when confronted with an increasing cost to prepare for an increasingly unlikely but possibly catastrophic event or trend (see Darmstadter and Toman 1993).

In complex systems like the Earth's carbon cycle, managerial participants (in this case, states) have varying degrees of risk aversion, different time-discount rates, different damage functions, and different propensities to free-ride on others' remedial action. Add to this varying political appreciations of scientific knowledge about the system's dynamics, and there is scant likelihood of consensus on governance. The intricacy and duration of the debates surrounding the Kyoto Protocol, thus far involving mainly the developed countries, are entirely predictable. 


\section{Present-time bias?}

P-E systems exist over time. They have some expected duration, if not an exact end point, well short of the life of the Earth itself. A future ice age will likely again cover large parts of the land surface in an ice sheet. In the nearer term, climate change within the next century is predicted to transform the species composition of many local ecosystems. Mounting uncertainties about environmental and demographic conditions far ahead help to justify a degree of present-time bias in our outlook.

Specification of a time-discount rate is in one sense a boundary-setting devicean alternative to specifying a terminal point for the system, a time beyond which its state is disregarded. ${ }^{10}$ But it is also necessarily a valuation issue. At a 3 percent per year discount rate, a particular environmental impact a generation hence is deemed to be equivalent to around half the same impact occurring now. "Constitutional" provision for ecosystem conservation — setting boundaries and prohibitions that it is intended should never be abridged-are effectively imposing a zero discount rate. Planning of P-E systems concerned with high-level nuclear waste disposal, at least in the United States, assumes a virtually zero discount rate, with containment chambers required to last many millennia-although how much of this is insincere accommodation of populist sentiment is hard to gauge. An implied discount rate that would not trivialize environmental matters a mere lifetime away could not be greater than 1 or 2 percent per year.

Time-discounting is deemed inadmissible by some analysts. Shue (1999) investigates the rights of future generations in resource and environmental policy, both property rights and the fundamental and nonmarketable right of physical security. Such rights, he asserts, should not be attenuated by discounting ("which values everything from one's own point of view exclusively"), let alone by application of a net present-value criterion. ("Whatever may be the correct approach, simply maximizing the net present value is certainly not it.") He comes down to a stance that might be described as ethical sustainability: "we are prohibited from engaging in any practices that will make it impossible for people in the future to enjoy their basic rights when, but for our choosing to engage in those practices rather than other practices open to us, they could have enjoyed their basic rights too" (p. 49). 
An alternative means of ethical assessment is the Rawlsian device of a veil of ignorance applied intertemporally, with the notional persons behind the veil required to decide on environmental policy without knowing which generation they will be part of. (This procedure is akin to the philosophical assumption of "tenselessness": people yet to be born — but who will be born — are laid out as simultaneous claimants on environmental resources.) The result is likely to favor a strong conservationist ethic.

\section{Adaptive preferences}

Over real time, in contrast to that tenseless world, people's tastes and values change. "Wilderness," for example, was once a feared environment, a region awaiting the civilizing influence of human settlement, not an object of protective concern. ${ }^{11}$ Aesthetic valuations evolve and change with social and economic development, as more basic consumption needs are satisfied and as leisure time expands.

Tastes and values also adjust to environmental actualities. We are acculturated to our environments and in some measure change along with them. Over long time periods, especially with generational turnover, people adapt to new environmental conditions and regret ebbs or vanishes. Present-day European populations, ever willing to demonstrate strong support for reducing tropical deforestation, do not pine for the temperate forests of the Dark Ages, let alone work to reestablish them-although some natural reforestation is occurring as a byproduct of agricultural and demographic change. Indeed, it is the human-transformed agrarian landscapes of field and hedgerow that are often deemed in need of preservation.

\section{Human and environmental ethics}

In valuing human wellbeing how do we account for changes in population numbers? Congestion effects detract from a person's enjoyment of an environmental amenity, but more people are able to share the experience: is there a gain in overall human welfare? If the people are already nearby, waiting at the gates, and if the detraction is not too large, the answer may well be yes-though environmental protection may require some kind of rationing or queueing. If the people are purely notional-far removed geographically, or not yet born (as in Malthus's famous image of the intruders at Nature's 
Feast) - the intuitive answer would probably be no, although sorting through the implications of that position leads rapidly to an ethical morass. I return to the issue of "excludability" in the discussion of governance below.

But do such calculations apply across national borders or only within them? The question arises in considering whether countries are responsible for their population growth-or, more precisely, for their natural increase. UN conventions would seem to assume not: they assign a proliferating number of rights to individuals, often at the expense of "rights of society," with population growth (or decline) one outcome of the exercise of those rights. Rawls, the theorist of justice, might have been expected to agree, but in fact does not. He writes: “An important role of a people's government, however arbitrary a society's boundaries may appear from a historical point of view, is to be the representative and effective agent of a people as they take responsibility for their territory and its environmental integrity, as well as for the size of their population" (Rawls 1999: 39). The territory—and its capacity to support its population in perpetuity-is construed as an asset; the agent responsible for the maintenance of that asset is "the people themselves as politically organized." The people must "recognize that they cannot make up for their irresponsibility in caring for their land and its natural resources by conquest in war or by migrating into other people's territory without their consent" (ibid.). ${ }^{12}$

In the P-E context, human ethics must at some point be reconciled with environmental ethics. Demographers, hardly surprisingly, are anthropocentrists, as are nearly all social scientists. Anthropocentrists can be resolute environmentalists, strongly committed to ecological stability and willing perhaps to trade off appreciable human welfare to protect endangered species or sustain fragile ecosystems. These are plausible emphases in an individual's welfare function and can constitute a coherent "light green" ethical position. Under "deep-green" environmental ethics, P-E systems become simply Esystems.

Human history has seen a gradual expansion of the "moral community" to include all humans, in theory if not fully in practice. But that expansion halts at the species boundary. In welfare calculations, even grouping humans with other primates, a modest ethical extension and one fairly easily defended, would strike most practitioners as a far- 
fetched exercise. ${ }^{13}$ Attribution of a right to moral consideration to members of more distant species (a classic query in the environmental ethics literature is "Should trees have standing?") is still further removed from ordinary environmental politics and its ethical premises.

\section{DESIGN OF GOVERNING INSTITUTIONS FOR P-E SYSTEMS}

Management of environmental systems (E-systems) can draw on a body of accumulated experience recorded in the large conservationist literature. Except for commonpool resource systems, however, P-E systems have been less thoroughly explored. Findings for the most part are scattered in the literatures of human ecology, social anthropology, political science, and social and environmental history. The exception is important, but the special nature of CPR systems needs to be kept in mind: the principles of CPR management are not necessarily helpful in broader P-E contexts. At the other extreme of generality, work on what may eventually become a generic theory of institutional design offers some overall guidelines but is of little value on specific design issues. ${ }^{14}$

\section{CPR system governance}

Ostrom's major study of CPR systems looks at documented instances of longlasting systems, such as livestock management in Swiss alpine villages. From these cases she distills the following conditions for effective governance (Ostrom 1990: 90):

- Clearly defined resource boundaries and participants

- Rules for resource use appropriate for local conditions

- Participant involvement in rule-making

- Participant involvement in monitoring

- Graduated sanctions for rule violation; participant involvement in sanctioning

- Local, low-cost mediation to resolve conflicts

- Relative autonomy of CPR institutional arrangements from government interference

In addition, where there is a hierarchy of systems, the rules at each level must be compatible. 
Most actual CPR systems depart from such conditions-as they do from abstract models of iterated n-person, positive-sum games. They tend to be fragile and prone to breakdown. Monitoring may be onerous and enforcement difficult. Participants have incomplete information about the system and differing stakes in its preservation-and differing incentives for defection. "Participant involvement" may be little more than nominal, especially when numbers are large. Indeed, many systems that are potential candidates for CPR-type governance may never be able to set it up: among Ostrom's examples is the case of the Kirindi Oya irrigation system in Sri Lanka, "where no one cooperated with anyone else, and all lived in a hydrologic nightmare" (p. 214).

Formally, the oceans and the atmosphere are potential CPR systems, but with states rather than individuals as participants. States are acknowledged as equal sovereign entities in the rule-making process. However, that implies a radical inequality of representation in per capita terms and belies any direct analogue to small CPRs (see McNicoll 1999). The cases are better treated as general P-E systems.

\section{General P-E system governance}

Most P-E systems do not show the symmetry among participants needed for CPR governance, with its prospect of positive-sum strategies through cooperative action. More common are systems containing unilateral transfers-where environmental exploitation yields gains to some participants but is accompanied by a shedding of costs to others. Favorable environmental outcomes might then require paying off the losers. In addition to working out such compensation arrangements, major governance issues include devising a satisfactory compliance regime and adapting to changes in supervening conditions - not least, dealing with population change.

Transfers and compensation. In a private property regime, the allocation of gains among system participants is largely determined by the distribution of ownership and access rights. Historical inequities in the establishment of those rights can often be pointed to but are rarely a factor in that allocation. The main governance task is ensuring containment of negative spillovers, whether among participants or to outsiders. Where a commons is involved, there is a prior problem of devising and supervising the allocation rules on exploitation — frequently a highly intricate and politically laden task. A further 
governance concern may be that of trying to prevent shirking of responsibilities for system maintenance.

Many P-E systems are socially underbounded. They reward their participants while transferring some of the costs of environmental exploitation to others. In effect, in terms of the earlier discussion of boundaries, the system is construed as if it contained only P2. Those excluded may be in a different country or be members of a politically marginalized class or ethnic group or simply be too few to be politically significant. Where the number of potential claimants is large, the harm to each may be comparatively slight, making it difficult to organize them to assert the claim - a familiar impediment to collective action (Olson 1965) and one that in the P-E case routinely results in heavy aesthetic losses. Hence it is entirely possible for a P-E system apparently to yield a sustainable environmental outcome together with satisfied immediate beneficiaries, whereas the level of satisfaction would be judged very differently if all the participants in the properly bounded system were included.

River systems often exemplify such a situation, with downstream users having limited recourse against changing upstream use. One community's levees for flood control shift the flood risk to other communities. Despite their formal position as a supervening authority, national political systems are poorly organized to preclude such cost shedding or to compensate for it. Economic development inevitably brings an uneven incidence of gains and losses across regions - a byproduct of policies that deal with citizens by characteristics other than location - and this would simply be seen as another such case, not specific enough for government economic redress or for tort action by the victims. Moreover, within a state there is often little the downstream propertyholders or communities can bargain with or threaten. Remedy is more likely in situations where international borders are involved, where the claimants are already mobilized as sovereign states and can draw on the precedents and options of international relations. Over the next decade or two, for example, the Euphrates and Tigris waters available to Syria and Iraq will be much diminished by the completion of Turkey's Southeastern Anatolia Project, a vast irrigation and hydropower scheme. India's construction of the Farakka Barrage, diverting Ganges water toward Calcutta, diminishes the lowseason flow to Bangladesh. Future upstream damming of the Nile will restrict Egypt's 
irrigation. The treaties arrived at for sharing the resource in such cases can draw on the limited amount of international law on the subject but in the main reflect the geographic advantage of the upper riparian state and the relative economic (and, in the background, military) power of the parties.

Changes in atmospheric composition through chlorofluorocarbon (CFC) or greenhouse gas emissions are global P-E systems with significant unilateral transfers. Negotiations among the industrialized states to restrict emissions proceeded as if the problems were those of CPR governance (the resource in each case being the atmosphere as sink), but when they encompassed the developing countries as well, the asymmetries had to be dealt with. In the CFC case, the G-77 bloc-essentially, the developing countries-was initially unwilling to assent to the draft Montreal Protocol; success came only when India, as the leading G-77 member, was persuaded, which "was attained through a process which framed ozone protection as a North-South conflict, not a commons dilemma" (see Herring 1999: 220). The modified agreement incorporated both technology sharing and some direct compensation for transition costs. In the greenhouse case, the international transfers that have to be anticipated in a carbon-trading governance regime, already large among the developed-country signatories to the Kyoto Protocol, would be potentially much larger still with inclusion of the developing countries-some of them soon to be among the biggest $\mathrm{CO}_{2}$ emitters.

Compliance and sanctions. In small CPR systems, compliance with the rules of participation can often be ensured by a combination of internalized behavioral norms and informal social pressures-with the sanctions of social ostracism or exclusion typically available as backup. In larger and less symmetrical systems, the rules are necessarily more complex and the procedures for ensuring compliance have to be more formal, though these may supplement rather than replace the informal procedures.

Pettit (1996: 72-87) distinguishes two general approaches to compliance, which he terms deviant-centered strategies and complier-centered strategies. A deviant-centered strategy is that of deterrence, one that seeks to impose a sanction on a noncomplier sufficient to cause regret to the offender. It has two problems, Pettit argues: the power necessarily given to whoever oversees the sanctioning process, and the tendency it has to force all agents into "egocentric deliberation"- a calculating mode in which they 
examine their own best interests in deciding whether or not to comply rather than acting on principle, which most would otherwise be inclined to do. A complier-centered strategy, in contrast, is concerned to reinforce the actions of agents who tend for the most part not to act in an egocentric way. The latter can be accomplished partly by screening out the most likely noncompliers and partly by choosing sanctions that promote nonegocentric deliberation-for example, by use of "shaming," as in the practice of reprobative justice.

Most large P-E systems rely on the first of these approaches. Explicit treaty provisions are likely to be involved, and elaborate quasi-legal compliance systems are inescapable. Where it is feasible, however, the second approach would be less costlyperhaps progressively so-and probably less onerous. An efficient option may be to combine the two, restricting formal sanctioning to a small residue of recalcitrants. ${ }^{15}$

International P-E systems where the participants are states illustrate the problems of designing compliance regimes. In the strict sense the international sphere is anarchic but certainly not ruleless or unordered. Compliance in a system may be enforced by prescribed treaty sanction or by unilateral action by an important player. But equally, it may be voluntary, as befitting a good international citizen; or it may be sustained by social pressure from the "international community" or by fear of notoriety. Institutional arrangements regulating behavior do not necessarily require a supervening organization: those arrangements themselves constitute a regime and may be sufficiently entrenched to be self-enforcing or nearly so. ${ }^{16}$

Consider the compliance problems of the Kyoto Protocol. Under the protocol, each country is required to provide an "annual inventory of anthropogenic emissions by sources and removals by sinks of greenhouse gases," and enough supplementary information "necessary to demonstrate compliance." There is provision for "expert review teams" under the auspices of the Conference of the Parties or its secretariat to assess these reports, and there are (as yet unspecified) penalties for noncompliance. (See Grubb et al. 1999.) All this is clearly deviant-centered. But alongside that apparatus, it is certain that there will be an array of NGOs and IGOs (Greenpeace, or AOSIS [Association of Small Island States], for example) engaged in identifying and shaming treaty violators. We already see the influence of such organizations in publicizing departures or apparent departures from environmental good behavior-and their effect on both pri- 
vate-sector and government actors. Increasingly, such organizations are being given (or assume) roles in regime design negotiations and in official monitoring. ${ }^{17}$

Compliance issues that might entail penalizing or rewarding population change are especially sensitive, reflecting the status of that subject in the international discourse on human rights. The same organizations that routinely hold governments to account on environmental matters largely avoid any suggestion that demography might warrant similar attention. The reluctance of the 1992 Earth Summit to deal with population matters and the dispensing with any mention of demographic targets in the 1994 Cairo Program of Action were notable cases in point.

Population growth and excludability. Governance of a P-E system requires a determinate population and hence rules for inclusion as a participant. Sustainable exploitation of a renewable resource cannot be achieved under open access. If participant numbers are allowed to rise, per capita yields must be correspondingly reduced; there is thus a strong incentive for existing participants to exclude newcomers. Inmigrants to a community often do not automatically acquire environmental access. Some traditional communities not only accord greater resource rights to original settlers than to later migrants, but also apply that same distinction even to distant descendants of the two groups. Within states, the practice of recognition of citizenship by birth and liberal rules on the incorporation of new entrants may be at odds with, and give way to, ethnic or cultural solidarity asserting a supposedly prior claim to resource access.

In a loose sense, a nation-state is itself a $\mathrm{P}-\mathrm{E}$ system - the $\mathrm{P}$ its total population, the $\mathrm{E}$ its terrestrial and coastal marine natural environment. Population growth dilutes access rights and, without stringent rules on exploitation, may harm environmental conditions. A state has virtually complete authority over immigration but has little regulatory power over the highly decentralized processes of natural increase. Most states with high fertility have sought to extend the practice of birth control, but through mild and voluntaristic measures nominally aimed at meeting an existing demand by families. They tolerate congestion effects on environmental amenity or dilution of per capita resource supplies as preferable to the political and human costs of rigorous control. China and Vietnam have been the principal exceptions—-both seeking to cap family size, albeit with a broad developmental rationale rather than out of concern for environmental sustainability. At smaller social scales, community control of fertility (or equivalently, 
of marriage or household establishment) is more common, at least historically: numerous such practices existed in preindustrial Europe, Japan, and probably China (see McNicoll 1975; Lee and Wang 1999).

At the international level, in P-E systems with nation-states as participants, differential population growth might be supposed to be an important issue in regime design. Over the next several decades some countries anticipate another population doubling or more; others will begin to experience significant declines in numbers. In practice, however, allocative decisions concerning access rights to the few remaining global commons have thus far been made with scant interest in existing population relativities, let alone in anticipated changes in relativities. ${ }^{18}$ Neither counted for much in the Law of the Sea negotiations. In current discussions on carbon emission targets to control the greenhouse effect, per capita equity across states has not been a major concern, though it may yet become a consideration.

\section{Prospects For Population-EnVironment System MANAGEMENT}

Management of a population-environment system is a kind of holding action in an already transformed environment, pursuing the gains from exploitation of that environment while limiting (further) "adverse" changes in it—and perhaps even achieving some degree of repair. The management task is made more difficult if there are unclear or contested boundaries, large numbers of participants, complex system dynamics and outcome indicators, or unequal stakes by participants. The more important systems usually have just those qualities.

Management success from an environmental standpoint is judged in terms of sustainability. This is not a clear-cut concept, often lacking any specification of what is to be sustained. ${ }^{19}$ Further difficulties in judging outcomes arise from the fact that $\mathrm{P}-\mathrm{E}$ systems are never fully autonomous, even in physical terms. One overlaps another, sharing components; smaller systems are parts of larger ones. Knowledge of a system's dynamics can never be complete, and each is subject to changes originating beyond the control of its human participants, and partly or wholly unanticipated. A sustainable outcome calls for agility in management response on continually shifting ground. 
This is also true of environmental systems alone, where the objective is to protect part of the natural world from degradation. Thus, for example, forest ecosystems, however competently managed, will be transformed by atmospheric warming; the accidental spread of organisms and species across widely distant regions, an inevitable consequence of human activity, can destroy unique regional biota; a massive collective effort may slow the growth of anthropogenic carbon emissions, but it does nothing about natural sources of climate change. Active human intervention is often required to preserve "naturalness."

P-E system outcomes are subject not only to changes in surrounding ecological conditions but also to changes in their institutional context. Any governance regime relies on established patterns and expectations concerning social relationships: respect for contractual understandings, the backing of a legal order or its equivalent in customary law, and the inadmissibility of force in dispute resolution. If that stability breaks down, the system is likely to fail, both socially and environmentally.

Population growth is one evident threat to that stability. Generational doublings in population size, a familiar modern phenomenon, put a large stress on institutional arrangements for capping resource exploitation at sustainable levels. The gains to a system's participants may be heavily diluted, undermining its rationale; the numbers of would-be participants at the boundaries increase, challenging its restriction on access rights; the likelihood of system failure is increased. Such a threat is of course alleviated to the extent that capital investment and technological advances generate sufficient expansion in non-resource-intensive sectors of the economy, drawing labor into new industries and the population into new kinds of consumption-including, typically, the "consumption" and thus the protection of environmental amenity.

The course of modern demographic transition has seen a worldwide surge in population growth caused by economic and public health achievement, followed by successive country declines in growth as lower fertility takes hold. In many cases, the population surge has been accompanied by extensive environmental degradation—albeit through ignorance as much as through institutional malfunction. As affluence and environmental sensibilities increase, an effort may be made to remedy the damage.

For the world as a whole, population decline is still a distant prospect. The UN medium-variant trajectory, in the 1998 projections, reaches more than 10 billion in two 
centuries, although it is already at 9 billion by 2050. (Some other analysts expect the peak to be closer to 8 billion, and attained this century.) What is the likely scenario for the global P-E system, where $\mathrm{E}$ is the planetary environment as a whole? We cannot yet know whether the peak global population and the disruptive technologies it employs in the path to postindustrial, aged, and perhaps environmentally benign affluence will leave a permanently impoverished natural world or one that can in large measure repair itself. Indeed, we cannot even say much about the likely future quality of the built environment-the immediate surroundings of most of humanity.

"Planetary management" is the title of a concluding section in Smil's Global Ecology (1993), but Smil sees little hope in such a thing. ${ }^{20}$ Global environmental problems, perhaps fortunately, lack a global Hobbesian Leviathan to sort them out. Smil points to the "design and implementation perils of grand schemes and massive bureaucracies" (p. 211) — a theme taken up in a different context by Scott (1998). Smil's preferred way ahead is through country-specific actions, taken in the interests of each country itself (though not of course at the expense of others) - actions that have their own rewards and are not necessarily dependent on the validity of current knowledge of environmental systems, let alone notional values of yet-to-be-discovered environmental goods and services.

But there are global problems likely to require a concerted response. For that task, what we have, organizationally, is the society of states, together with international institutions like the UN whose constituents are states, and a more diffuse "international community" of NGOs, IGOs, and other bodies that in combination are sometimes referred to as global civil society. The society of states confronting a global commons is in some respects a scaled-up analogue of a local community seeking to deal with a depleted aquifer or fishery without recourse to government. The major difference, of course, is that states as actors, assigned nominal equality as sovereign entities, disguise radically diverse population sizes. Hence there are always two (at least) equity claims in play: that of equality of state sovereignty and that of equality of human rights. Both claims would often be dominated by a third: that conferred by the economic or military power of states, in isolation or alliance. 
Revised version of a paper prepared for the Seminar on Methods of PopulationEnvironment Analysis, Penang, 10-11 April 2000, organized by the Asian MetaCentre for Population and Sustainable Development Analysis and the International Centre for Living Aquatic Resource Management (ICLARM). Comments by Adrian Hayes are acknowledged.

1 Intentionality may have been present at a lower systemic level. Thus in Australian prehistory, nomadic groups used forest burning to create grasslands that would attract game. The unintended higher-level systemic outcome, it is argued, was the spread of fire-resistant tree species and, more speculatively—through a series of related effects—a drying of weather patterns. (See Flannery 1994.)

2 The "critical environmental zones" identified by Kasperson et al. (1995)—regions with seriously endangered ecologies resulting from human activities—are all delimited in terms of geographic ecosystem boundaries, and their degradation often can be tied to the political difficulty of constructing an appropriate administrative authority. The nine regions in this study are: Amazonia; Eastern Sundaland (Java, Sumatra, Peninsular Malaysia, and Kalimantan); the Ukambani of eastern Kenya; the settled uplands of Nepal; the Ordos Plateau of Inner Mongolia; the Aral Sea basin; the Southern High Plains and Ogallala aquifer in northwestern Texas; the Basin of Mexico (surrounding Mexico City); and the North Sea.

3 Singer's hierarchy of species in descending order of moral considerability is based on assessments of relative neural complexity. But it maps poorly onto the hierarchy of species accorded actual protection from hunting or consumption as food in most human cultures. (See Singer 1990.)

4 The Chernobyl case is formally analogous. The airshed that was subject to radioactive contamination in 1986 covered a large populated region beyond Ukraine. The governments representing this cross-border P3 population have agreed to contribute to the costs of closing the Chernobyl plant.

$5 \quad \mathrm{CO}_{2}$ emissions are assessed by the equivalent forest area required for sequestration. 
6 For six West African countries, Leach and Fairhead cite the World Conservation Monitoring Centre as estimating an area of 48 million hectares lost to forest over the twentieth century; their own estimate of the loss, based on a more realistic calculation of the baseline, is some 10 million hectares. They challenge both the depiction of a "natural" undisturbed forest before the modern era of rapid population growth and the view that farming and settlement can only damage forests.

7 Unless such migration exacerbates environmental decline-as, for instance, in the case of the once-spectacular Ifugao rice terraces of Luzon, decaying from lack of maintenance.

8 See, for example, Murray-Darling Basin Commission (1999). (The Murray-Darling river basin, subject to severe irrigation-related salination, extends over an area of 100 million hectares in eastern Australia.)

9 This principle, as it appears in the 1992 Rio Declaration (Principle 15), reads: "Where there are threats of serious or irreversible damage, lack of full scientific certainty shall not be used as a reason for postponing cost-effective measures to prevent environmental degradation."

10 Economists' treatment of depreciation is analogous. A constant time-rate of depreciation is usually preferred to setting a fixed lifetime of an investment-the so-called one-hoss shay assumption.

11 Cf. Alfred Marshall (1890: ch. 13, para. 3 fn): “The Englishman [J.S.] Mill bursts into unwonted enthusiasm when speaking [in his discussion of the stationary state] of the pleasures of wandering alone in beautiful scenery: American economists from Carey to Henry George no less characteristically use their highest eloquence in splendid descriptions of the growing richness of human life as the backwoodsman finds neighbours settling around him, as the backwoods settlement develops into a village, the village into a town, and the town into a vast city."

12 Rawls somewhat casually dismisses concerns about the highly unequal per capita distribution of natural resources by remarking that "the crucial element in how a 
country fares is its political culture-its members' political and civic virtuesand not the level of its resources, [hence] the arbitrariness of the distribution of natural resources causes no difficulty" (Rawls 1999: 117).

13 That, however, is the agenda of the ethically well-grounded Great Ape Project. See www.greatapeproject.org.

14 See Goodin (1996a: 39-43). Goodin's tentative principles of institutional design call for revisability (within limits), robustness (to changing circumstances, within limits), sensitivity to motivational complexity (including "designing institutions for knaves"), public defensibility, and variability (to allow learning by doing and experimentation).

15 Cost-effectiveness is not the only basis for choice of compliance strategy-or a governance regime in general. Dryzek (1996) argues that market-based responses to environmental problems - pollution charges, emissions trading, etc.—although seen by economists as generally preferable in efficiency to regulatory measures, are objected to by many environmentalists precisely because they fail to stigmatize the behavior. Pollution is not made to seem morally wrong.

16 See Young (1989: 37-44). International organizations increasingly seek to add that formal supervention in specific functional areas.

17 The CITES treaty (Convention on International Trade in Endangered Species) is administered by international NGOs - the IUCN and WWF-agencies that have no formal policing authority but that can monitor species conditions, publicize emerging crises, and direct opprobrium at offending states.

18 During its brief period of Emergency rule in the 1970s, India's government sought to end population-based adjustments to the allocation formula for federal grants to the states, thereby penalizing high-fertility states.

19 See the essays in Dobson (1999) for some contrasting views. An interpretation in terms of maintenance of "natural capital" merely adds another definitional problem.

20 "The grandest of these co-operative approaches" would be a global compact be- 
tween rich and poor countries, trading off "a drastic reduction of energy and material use in the rich countries in return for the commitment to an early achievement of replacement fertilities in the poor world"-a scheme proposed by John Holdren (Smil 1993: 208).

\section{References}

Darmstadter, Joel and Michael A. Toman (eds.). 1993. Assessing Surprises and Nonlinearities in Greenhouse Warming: Proceedings of an Interdisciplinary Workshop. Washington, DC: Resources for the Future.

Dobson, Andrew (ed.). 1999. Fairness and Futurity: Essays on Environmental Sustainability and Social Justice. Oxford: Oxford University Press.

Dore, Mohammed H.I. and Timothy D. Mount (eds.). 1999. Global Environmental Economics: Equity and the Limits to Markets. Oxford: Blackwell.

Dryzek, John S. 1996. "The informal logic of institutional design,” in Goodin (1996b). Flannery, Tim. 1994. The Future Eaters: An Ecological History of the Australasian Lands and People. Sydney: Reed.

Goodin, Robert E. 1996a. "Institutions and their design," in Goodin (1996b). (ed.). 1996b. The Theory of Institutional Design. Cambridge: Cambridge University Press.

Grubb, Michael, Christiaan Vrolijk, and Duncan Brack. 1999. The Kyoto Protocol: A Guide and Assessment. London: Royal Institute of International Affairs.

Harwell, Emily E. 2000. "Remote sensibilities: Discourses of technology and the making of Indonesia's natural disaster," Development and Change 31: 307-340.

Herring, Ronald. 1999. "Market-restructuring regulation and the ozone regime: Politics of the Montreal Protocol," in Dore and Mount (1999).

Ives, Jack D. and Bruno Messerli. 1989. The Himalayan Dilemma: Reconciling Development and Conservation. New York: Routledge. 
Kasperson, Jeanne X., Roger E. Kasperson, and B.L. Turner II (eds.). 1995. Regions at Risk: Comparisons of Threatened Environments. Tokyo: United Nations University Press.

Leach, Melissa and James Fairhead. 2000. "Challenging neo-Malthusian deforestation analyses in West Africa's dynamic forest landscapes," Population and Development Review 26: 17-43.

Lee, James Z. and Wang Feng. 1999. One Quarter of Humanity: Malthusian Mythology and Chinese Realities, 1700-2000. Cambridge, MA: Harvard University Press.

Lipschutz, Ronnie D. 1996. Global Civil Society and Global Environmental Governance: The Politics of Nature from Place to Planet. Albany: State University of New York Press.

Marshall, Alfred. 1890. Principles of Economics. London: Macmillan.

McNicoll, Geoffrey. 1975. "Community-level population policy: An exploration," Рориlation and Development Review 1: 1-21.

— 1999. "Population weights in the international order," Population and Development Review 25: 411-442.

Murray-Darling Basin Commission. 1999. The Salinity Audit of the Murray-Darling Basin: A 100-Year Perspective, 1999. Canberra.

Olson, Mancur. 1965. The Logic of Collective Action: Public Goods and the Theory of Groups. Cambridge, MA: Harvard University Press.

Ostrom, Elinor. 1990. Governing the Commons: The Evolution of Institutions for Collective Action. Cambridge: Cambridge University Press.

Pettit, Philip. 1996. "Institutional design and rational choice," in Goodin (1996b).

Rawls, John. 1999. The Law of Peoples. Cambridge, MA: Harvard University Press.

Rees, William E. 1996. "Revisiting carrying capacity: Area-based indicators of sustainability," Population and Environment 17 (http://dieoff.com/page110.htm)

Scott, James C. 1998. Seeing Like a State: How Certain Schemes to Improve the Human Condition Have Failed. New Haven: Yale University Press. 
Shue, Henry. 1999. "Bequeathing hazards: Security rights and property rights of future humans," in Dore and Mount (1999).

Singer, Peter. 1990. Animal Liberation. 2nd ed. New York: New York Review of Books.

Smil, Vaclav. 1993. Global Ecology: Environmental Change and Social Flexibility. New York: Routledge.

— 2000. "Population and environmental services." Paper prepared for the Seminar on Methods of Population-Environment Analysis, Penang.

Vitousek, P.M., H.A. Mooney, J. Lubchenco, and J.M. Melillo. 1997. "Human domination of Earth's ecosystems," Science 277: 494-499.

Wackernagel, M. and W. Rees. 1996. Our Ecological Footprint: Reducing Human Impact on the Earth. Philadelphia: New Society Publishers.

Young, Oran R. 1989. International Cooperation: Building Regimes for Natural Resources and the Environment. Ithaca: Cornell University Press. 


\section{POLICY RESEARCH DIVISION WORKING PAPERS}

Recent Back Issues

1998

*106 Sajeda Amin and Gilda Sedgh, "Incentive schemes for school attendance in rural Bangladesh."

107 Martin Brockerhoff and Paul Hewett, "Ethnicity and child mortality in sub-Saharan Africa."

108 Ann E. Biddlecom and Bolaji M. Fapohunda, "Covert contraceptive use: Prevalence, motivations, and consequences."

109 John Bongaarts and Griffith Feeney, "On the quantum and tempo of fertility."

110 Barbara S. Mensch, Daniel Bagah, Wesley H. Clark, and Fred Binka, "The changing social environment for adolescents in the Kassena-Nankana District of northern Ghana: Implications for reproductive behavior."

111 Martin Brockerhoff and Ann Biddlecom, "Migration, sexual behavior, and HIV diffusion in Kenya."

112 Zeba A. Sathar and John B. Casterline, "The onset of fertility transition in Pakistan."

113 Geoffrey McNicoll, "Government and fertility in transitional and posttransitional societies."
*114 John Bongaarts, "Fertility and reproductive preferences in post-transitional societies."

115 Fiona Steele, Sajeda Amin, and Ruchira T. Naved, "The impact of an integrated micro-credit program on women's empowerment and fertility behavior in rural Bangladesh."

*116 Cynthia B. Lloyd, Barbara S. Mensch, and Wesley H. Clark, "The effects of primary-school quality on the educational participation and attainment of Kenyan girls and boys."

*117 Sajeda Amin and Cynthia B. Lloyd, "Women's lives and rapid fertility decline: Some lessons from Bangladesh and Egypt."

118 James F. Phillips and Mian Bazle Hossain, "The impact of family planning household service delivery on women's status in Bangladesh."

*119 Mark R. Montgomery and John B. Casterline, "Social networks and the diffusion of fertility control."

* No longer available 
*120 John Bongaarts, "The fertility impact of changes in the timing of childbearing in the developing world."

*121 James F. Phillips, Wendy L. Greene, and Elizabeth F. Jackson, "Lessons from community-based distribution of family planning in Africa."

122 Mark R. Montgomery, "Mortality decline and the demographic response: Toward a new agenda."

*123 Mark R. Montgomery, Mary ArendsKuenning, and Cem Mete, "The quantity-quality transition in Asia."

124 Barbara S. Mensch, Wesley H. Clark, Cynthia B. Lloyd, and Annabel S. Erulkar, "Premarital sex and school dropout in Kenya: Can schools make a difference?"

125 John Bongaarts and Rodolfo A. Bulatao, "Completing the demographic transition."

126 Geoffrey McNicoll, "Population weights in the international order."
127 Cynthia B. Lloyd, Carol E. Kaufman, and Paul Hewett, "The spread of primary schooling in sub-Saharan Africa: Implications for fertility change."

128 John B. Casterline, "The onset and pace of fertility transition: National patterns in the second half of the twentieth century."

129 Mark R. Montgomery, Michele Gragnolati, Kathleen Burke, and Edmundo Paredes, "Measuring living standards with proxy variables."

130 Bamikale Feyisetan and John B. Casterline, "Fertility preferences and contraceptive change in developing countries."

131 Martin Brockerhoff, "Urban growth in developing countries: A review of projections and predictions."

132 Omaima El-Gibaly, Barbara Ibrahim, Barbara S. Mensch, and Wesley H. Clark, "The decline of female circumcision in Egypt: Evidence and interpretation."

* No longer available 
133 Mary Arends-Kuenning and Sajeda Amin, "The effects of schooling incentive programs on household resource allocation in Bangladesh."

134 John Bongaarts and Charles F. Westoff, "The potential role of contraception in reducing abortion."

135 John B. Casterline and Steven W. Sinding, "Unmet need for family planning in developing countries and implications for population policy."

136 Carol E. Kaufman, Thea de Wet, and Jonathan Stadler, "Adolescent pregnancy and parenthood in South Africa."
137 Valerie L. Durrant and Zeba A. Sathar, "Greater investments in children through women's empowerment: A key to demographic change in Pakistan?"

138 Sajeda Amin, Alaka Malwade Basu, and Rob Stephenson, "Spatial variation in contraceptive use in Bangladesh: Looking beyond the borders."

139 Geoffrey McNicoll, "Managing population-environment systems: Problems of institutional design." 